\title{
“GERM INFECIOSO" NAS CULTURAS ESCOLARES - possibilidades e limites da política de autonomia e flexibilização curricular em Portugal
}

\author{
Paulo Marinho \\ Universidade do Porto - UP \\ Carlinda Leite \\ Universidade do Porto - UP \\ Preciosa Fernandes \\ Universidade do Porto - UP
}

\begin{abstract}
Resumo
Estudos focados em orientações que comandam muitas das políticas curriculares e de avaliação internacionais referem que elas têm seguido lógicas de padronização que as inserem em uma Global Educational Reform Movement (GERM). Tendo este movimento por referência, foi realizado um estudo que teve como objetivo identificar e analisar possibilidades e limites da medida política de Autonomia e Flexibilidade Curricular implementada em Portugal em 2017/2018 constituir uma contracultura ao "GERM infecioso" das políticas globais. Os dados foram obtidos através da análise de relatórios elaborados por agrupamentos de escolas envolvidas nesta política, no ano de experimentação. A análise desses relatórios permitiu concluir que se trata de um projeto com possibilidades de se constituir em um potencial antídoto neutralizador dos efeitos do GERM. Contudo, na sua concretização são assinaladas limitações várias resultantes, quer de uma aculturação das escolas e dos professores a princípios de uma sociedade homogénea e homogeneizadora, quer da falta de condições para que os professores se assumam enquanto agentes de decisão.
\end{abstract}

Palavras-chave; Autonomia; Flexibilização curricular; Políticas de educação; Culturas escolares; GERM.

\begin{abstract}
Studies that focus on guidelines that command many of the international curriculum and assessment policies report that they have followed standardization logics that insert them into a Global Educational Reform Movement (GERM). Taking this movement as a reference, a study was conducted to identify and analyze possibilities and limits of policy measure of Autonomy and Curricular Flexibility, implemented in Portugal in 2017/2018, to constitute a counterculture to the “infectious GERM” of global policies. Data were obtained through the analysis of reports prepared by groupings of schools involved in this policy, in year of experimentation. The analysis of these reports led to conclusion that this is a project with possibilities to constitute a potential antidote to neutralize the effects of GERM. However, in its implementation several limitations are pointed out, resulting either from the acculturation of schools and teachers to principles of a homogeneous and homogenizing society, and from the lack of conditions for teachers to assume themselves as decision makers.
\end{abstract}

Keywords: Autonomy; Curricular flexibility; Education policies; School cultures; GERM.

ISSN 1645-1384 (online) www.curriculosemfronteiras.org

http://dx.doi.org/10.35786/1645-1384.v19.n3.07 


\section{Introdução}

Historicamente, um pouco por toda a Europa, os sistemas educativos, ainda que sob a retórica da autonomia, têm estado prisioneiros de políticas globais centralistas. Estas políticas, que demandam orientações curriculares e processos de avaliação estandardizados, são concebidas, muitas vezes, numa lógica de total distanciamento com as características dos territórios em que cada escola se situa. Enformadas por pressupostos neoliberais, essas diretrizes preconizam modelos curriculares e de avaliação padronizados (MARINHO; LEITE; FERNANDES, 2017) que empurram as escolas para lógicas de governação tecnocratas e sustentadas em rankings, e os professores para práticas curriculares "à prova de exames" nacionais e internacionais, isto é, focadas nos "conteúdos garantidos" para a realização desses exames. Estas situações empurram escolas, professores e alunos a imagens de sucesso e ou de fracasso, consoante a posição que ocupam nesses rankings de avaliações nacionais e internacionais, e que são tomados muitas vezes pelas sociedades e pelos cidadãos, em geral, como garantias de qualidade da educação.

Essas políticas estão associadas ao Global Educational Reform Movement - GERM (SAHLBERG, 2011, 2016; FULLER; STEVENSON, 2019), isto é, ao movimento que é conduzido por lógicas de padronização da educação no quadro de uma agenda global hegemónica liderada por organismos internacionais, como é o caso da OCDE e o do Banco Mundial. Trata-se de uma agenda difundida por regras, currículos prescritos e testes padronizados $^{1}$ que influenciam e determinam as políticas locais (SAHLBERG, 2005). Em linha com críticas deste movimento, alguns estudos têm concluído que a adoção pelos sistemas educativos de políticas que visam alcançar padrões internacionais pré-estabelecidos, com enfoques muito específicos tem conduzido a práticas de ensino e de aprendizagem mais “pobres” (FIGUEIREDO; LEITE; FERNANDES, 2019), pressionando as escolas e os professores a um exercício de controlo permanente que garanta o seu lugar no mercado (FULLER, 2018).

Pese embora esta situação, em alguns momentos da História recente têm emergido iniciativas políticas de caráter descentralista que se apoiam em discursos de maior autonomia e poder de decisão das escolas e dos professores (AFONSO, 2012; LEITE; FERNANDES, 2012). Uma análise atenta de algumas dessas medidas, no caso do sistema educativo português, mostra influências do GERM, nomeadamente no que se refere a emolduramentos de reformas educacionais ao serviço do mercado, embora sustentadas em discursos do paradigma da aprendizagem centrada no aluno e de razões que os justificam para alcançar melhores desempenhos educacionais locais e globais (SAHLBERG, 2016).

Face a um tão forte legado político de matriz hegemónica global, essas iniciativas, assentes, muitas vezes, num discurso inovador disfarçado, acabam por se constituir apenas em “ensaios políticos”, ainda que com fortes implicações nos quotidianos escolares, e nas lógicas e culturas de trabalho dos professores (COSME, 2018). É no quadro desta problemática que se situa o estudo de que este artigo dá conta. Nele são tidas por foco vivências curriculares ocorridas no âmbito da medida política de Autonomia e Flexibilidade Curricular (política iniciada em 2017, em Portugal) para se conhecer em que medida elas se 
constituem em ações contra hegemónicas e de rutura cultural com o GERM que se tem propagado nas escolas portuguesas. Reconhecendo que propostas curriculares apresentadas como "novas" ficam muitas vezes remetidas à natureza de “ensaio político”, o estudo recorreu aos relatórios de avaliação realizados pelas escolas que aderiam ao Projeto de Autonomia e Flexibilidade Curricular (PAFC) no final do primeiro ano da sua implementação. Nessa análise, foram identificadas potencialidades desta política curricular, mas também constrangimentos sentidos pelas escolas como seus limites, o que permite problematizar em que medida ela se está constituindo como contracultura ao "GERM infecioso” (SAHLBERG, 2011, 2016) de uma agenda padronizada global.

\section{GERM contaminante de reformas de educação}

O Movimento Global de Reforma da Educação tem sido usado metaforicamente por GERM (sigla em inglês) na tentativa de contribuir para a compreensão da complexidade de um cenário infecioso global hegemonizador, em contextos locais, de reformas educacionais, que segundo Sahlberg (2005), se transmite como um "vírus" que tem vindo a "matar a educação”. O GERM que, na perspectiva de Robertson (2015) e Sahlberg (2016), se desenvolve desde a década de 1980, surgiu originalmente nos Estados Unidos da América e no Reino Unido, baseado no paradigma neoliberal da prestação de serviços públicos. Depois dessa fase inicial, tem vindo a constituir um fenómeno global galopante, cada vez mais adotado como uma ortodoxia das reformas da educação dentro de muitos sistemas educacionais em todo o mundo. A sua expansão ocorre, frequentemente, por meio de interesses de agências internacionais de desenvolvimento e empresas privadas através de intervenções nas reformas de educação e formulação de políticas.

O GERM é, pois, um movimento que se apresenta com uma agenda educacional comum de ordem global realimentada por mecanismos transacionais que se articulam por meio de tentáculos operacionais para contextos locais. A OCDE, por meio do PISA (Programme for International Student Assessment), é um dos exemplos deste movimento, ao difundir determinadas orientações para a implantação de políticas educacionais que impactam tanto as práticas como os modos de gestão, nos processos da formação escolar, em geral, e nas dinâmicas de organização do currículo em particular (THIESEN, 2016). A este movimento associa-se o Banco Mundial e o Fundo Monetário Internacional para reafirmar e direcionar políticas educacionais, em particular em países em desenvolvimento. No entanto, a OCDE se tem destacado, globalmente, enquanto organismo governador das direções da educação (KUEHN, 2014), por meio de uma espécie de “doutrina de choque” (KLEIN, 2008), que tem por base uma "cultura de testagem” (BROADFOOT; BLACK, 2004; STOBART, 2008) e que assenta em dados e comparações tantas vezes descontextualizados. É nesse sentido que Sellar e Lingard (2013) referem que a OCDE emerge como ator político que ampara a formatação de sistemas educacionais locais tendo por base a ideia de ampliar a produtividade e sustentar o crescimento económico dos Estados nacionais. 
O desenvolvimento do GERM assenta em três princípios políticos principais responsabilização, padronização e descentralização -, tendo um vigoroso impacto nos contextos de ação, atingindo países que pareciam ser imunes a este movimento doutrinal de reforma da educação (VERGER; PARCERISA; FONTDEVILA, 2018). Pelos resultados que alcança, o GERM constitui a hegemonização de uma agenda educacional global. Essa agenda é constituída por normas, currículos prescritos, testes padronizados que fragmentam o sistema educativo, e em que as escolas e seus agentes são pressionados a controlar o desempenho e o sucesso e garantir o seu lugar no mercado (FULLER, 2018). Esta situação corresponde ao que Dale (2008) referiu como agenda globalmente estruturada para a educação e que Ball (2001, 2014) identificou como uma agenda político-económica mundializante que impacta a educação.

É também nesta linha que Macedo (2019) considera que muitas são as articulações políticas que procuram hegemonizar sentidos para uma educação de qualidade, em que os currículos nacionais são produzidos sob a hegemonia do discurso neoliberal e que Frangella e Dias (2018) criticam as BNCC (Base Nacional Comum Curricular) pela conceção de currículo em que se apoiam e pelo papel a que remetem os professores. Como argumenta Thiesen (2016), trata-se de uma agenda propositiva:

[...] em escala global ou transnacional que na educação, envolve pelo menos quatro grandes frentes, a saber: um movimento pela internacionalização curricular; a estratégia de centralização e/ou unificação curricular nas esferas nacional e regional; a universalização das avaliações em larga escala e o fortalecimento das chamadas parcerias público-privadas no território curricular. Em geral, na rota do discurso político e não raramente nos textos da política curricular oficial elas aparecem fixando sentidos em torno de conceitos como eficiência, inovação e qualidade (THIESEN, 2016, p. 92).

Convocando de novo Sahlberg (2011), o GERM tem assumido, entre outras, cinco características principais: i) Padronização da educação - trata-se de uma reforma educacional cujo foco de atenção são os resultados educacionais e que tem por base a crença de que a qualidade dos resultados melhorará se forem estabelecidos padrões de desempenho claros e suficientemente altos para escolas, professores e alunos (aplicação de sistemas externos de avaliação, currículos prescritos, entre outros); ii) Definição de disciplinas centrais como principais alvos de reformas educacionais - por exemplo, adotar os resultados de estudos internacionais de avaliação (PISA, TIMSS e PIRLS) como critérios de bom desempenho educacional, assumindo-se estes como principais determinantes do sucesso ou fracasso de alunos, professores, escolas e sistemas educacionais; iii) Procura de meios de baixo risco para atingir as metas de aprendizagem - o facto de se procurar limitar o risco a correr, nas escolas e nas salas de aula, não impulsiona, mas reduz o recurso a abordagens pedagógicas alternativas, contrariando dados da investigação dos sistemas educacionais que mostram que aqueles que adotaram políticas que priorizam temas centrais e seguem padrões predeterminados conduzem a práticas de ensino e aprendizagem mais restritas, orientadas 
para a preparação dos alunos para os testes; iv) Recurso a modelos de gestão corporativa como principais impulsionadores da melhoria - motivados não por objetivos do desenvolvimento humano, mas pela hegemonia nacional e lucro económico, emprestadas do mundo dos negócios a políticas e ideias educacionais; v) Adoção de políticas de responsabilização baseadas em testes para escolas - o sucesso ou fracasso de escolas e professores é frequentemente avaliado através de testes padronizados e avaliações externas, de forma redutora e descontextualizada, limitando-se a dimensões como o desempenho dos alunos em matemática e leitura e resultados em exames de final de ciclo, entre outros.

É nesse contexto que os discursos e as estruturas das agendas de educação global são constituídas e que as políticas de educação são disseminadas internacionalmente em ordens e lógicas hegemónicas de privatização e mercantilização da educação (VERGER; FONTDEVILA; ZANCAJO, 2016). São estes discursos hegemónicos que sustentam as demandas curriculares e educacionais e as justificam como necessárias para a escola e para a educação (LOPES, 2019). Trata-se, por vezes, de uma hegemonia disfarçada em discursos de neutralidade (REIS; CAMPOS; FLORES, 2016), que silencia possibilidades de ações contra hegemônicas. Talvez por isso, alguns países tenham começado por adotar o GERM não sustentados em enquadramentos para reformas pró-mercado na educação, mas apoiados pelos discursos do paradigma de aprendizagem centrado no aluno, defendendo-o como essencial para a melhoria do desempenho educacional (SAHLBERG, 2016).

No que à realidade portuguesa diz respeito, desde os anos 80 do século XX têm existido em Portugal algumas políticas que se enquadram nessa orientação discursiva, assumindo referenciais de uma cultura de sociedade de ordem global hegemónica pressionando e responsabilizando as escolas para processos de trabalho orientados apenas para os resultados finais. Para essas pressões concorrem, quer os compromissos políticos de uma agenda global, quer as que decorrem do fortalecimento das interações das escolas com o meio social. Exemplos de umas e de outras são: as avaliações impostas às escolas através da aferição estandardizada dos resultados obtidos pelos alunos; a valorização ou o prestígio das escolas decorrentes dos resultados obtidos em testes internacionais; as exigências das famílias que desejam para os seus filhos o sucesso imposto pela sociedade. É também no quadro desta pressão que, em muitos casos, os alunos são treinados para testes, centrados em currículos de núcleo comum (KUEHN, 2014).

Na linha do que sustentam Kamens e Mcneely (2010), as avaliações padronizadas têm sido vigorosamente utilizadas no contexto do movimento do GERM para implementar e monitorizar currículos padronizados e para o engendramento de processos de responsabilização das organizações escolares e seus agentes. É nesta senda que consideramos que também o sistema educativo português não tem ficado imune a esse movimento. Mobilizando discursos fundados em princípios de justiça, equidade e rigor, as políticas curriculares e de avaliação têm seguido orientações que se enquadram em alguns dos tentáculos do movimento GERM. Apenas para sustentar o que se está a afirmar, relembre-se a "cultura de testagem" iniciada no final do séc. XX, com a introdução de exames nacionais para os alunos da escolaridade básica (MARINHO; LEITE; FERNANDES, 2013). Esta cultura justificou que Barreira e Pinto (2005), em estudo sobre o ponto da situação das 
políticas de avaliação das aprendizagens em Portugal, a tenha considerado um regresso à “tolerância zero”. Posteriormente, isto é, já na primeira década deste séc. XXI, no desígnio de se instituir uma cultura de rigor e de excelência, as políticas seguidas pela equipa ministerial orientaram-se por lógicas neoliberais e neoconservadoras que reforçaram a cultura de uma sociedade global hegemónica de reformas curriculares e de políticas de accountability e de performatividade (BALL, 2003; AFONSO, 2009; LIMA, 2010; SCHNEIDER; NARDI, 2015; PACHECO, 2019). É esta cultura que tem invadido as escolas portuguesas e tem levado os professores a vivenciarem espaços, momentos e ambientes profissionais e organizacionais caracterizados por subculturas do cumprimento dos programas curriculares uniformes, realimentadas por uma "cultura global do número" (MARINHO, 2014). É também esta cultura que tem levado as escolas e os professores para conceções e práticas curriculares padronizadas e para o treino dos alunos nos conteúdos curriculares passíveis de serem testados nas provas de exame nacionais. Como tem sido demostrado, nestas práticas, o ensino e a aprendizagem são mais restritos, focando-se os professores no "conteúdo garantido" para melhor preparar os alunos para os testes de avaliação interna e externa (MARINHO; LEITE; FERNANDES, 2017).

É na sequência destas situações que, quase ao final da segunda década deste século, e procurando dar resposta a uma ordem hegemónica descontextualizada e descaracterizadora de problemáticas locais, o governo socialista que assumiu o poder em 2015 retomou uma medida política da governação socialista ocorrida nos finais dos anos 1990. Nessa altura, tal como agora, foi considerado que o currículo prescrito a nível nacional tem de ser recontextualizado a nível local (FERNANDES, et al, 2013), em função das situações reais.

No quadro desta situação, e considerando-se que as escolas e os professores portugueses estão a ser desafiados para modos de trabalho assentes em maior flexibilidade e autonomia curricular, e que outrora já foram por eles experienciados, pretende-se, como se referiu, analisar se a medida política em vigor a partir de 2017 em Portugal (PAFC) se constituiu, ou não, como uma contracultura ao "GERM infecioso" que se tem instalado nas culturas escolares.

\section{A política de autonomia e flexibilização curricular em Portugal}

Com a revolução de abril de 1974 iniciou-se em Portugal um movimento de democratização da sociedade e da educação, acompanhado de uma maior abertura ao mundo e às ideias que defendiam uma sociedade mais justa e uma instituição escolar que garantisse a igualdade de oportunidades de sucesso para todos os alunos que a ela passaram a aceder. Associada a estas ideias, a primeira Lei de Bases do Sistema Educativo (PORTUGAL, 1986), nos seus princípios, apontou como intenção uma rutura com a centralização que caracterizava o sistema português recorrendo à seguinte enunciação discursiva:

descentralizar, desconcentrar e diversificar as estruturas e ações educativas, de modo a proporcionar uma correta adaptação as realidades, um elevado sentido de 
participação das populações, uma adequada inserção no meio comunitário e níveis de decisão eficientes (PORTUGAL, 1986, Artigo 3. ${ }^{\circ}$, g).

A par desta intenção, começou a circular no vocabulário e nos discursos académicos, a palavra e o conceito de autonomia. Justificava-se essa autonomia como o meio de cada escola e cada grupo de docentes se mobilizarem em torno de projetos adequados a cada contexto social e, por isso, ser capaz de atender às especificidades dos distintos alunos. Foi em linha com esta orientação que a partir de 1989 a legislação portuguesa estabeleceu pela primeira vez o regime jurídico de autonomia das escolas (PORTUGAL, 1989), definindo princípios, sentidos e condições para a autonomia, administração e gestão dos estabelecimentos escolares. Apesar desse discurso, a autonomia decretada (BARROSO, 1996) foi muito limitada. Por um lado, foi associada à ideia de que a existência, por parte de cada escola, de maior autonomia criaria condições para que fossem melhor atendidas as situações com que convivia. No entanto, por outro lado, a autonomia que era conferida limitava-se a aspetos pedagógicos, e não aos organizacionais, e, mesmo assim, em campos muito restritos. São exemplo disso os seguintes enunciados legais:

Entende-se por autonomia da escola a capacidade de elaboração e realização de um projeto educativo em benefício dos alunos e com a participação de todos os intervenientes no processo educativo (PORTUGAL, 1989, Artigo $2^{\circ}$, 1, Cap. I).

O desenvolvimento da autonomia das escolas exige, porém, que se tenham em consideração as diversas dimensões da escola, quer no tocante à sua organização interna e às relações entre os níveis central, regional e local da Administração, quer assumir pelo poder local de novas competências com adequados meios, quer ainda na constituição de parcerias socioeducativas que garantam a iniciativa e a participação da sociedade civil (PORTUGAL, 1991, Preâmbulo).

A extensão da autonomia depende da dimensão e da capacidade do agrupamento de escolas ou escola não agrupada e o seu exercício supõe a prestação de contas, designadamente através dos procedimentos de auto avaliação e de avaliação externa; A transferência de competências da administração educativa para as escolas observa os princípios do gradualismo e da sustentabilidade" (PORTUGAL, 2008, Cap. II, Artigo 8º).

Legislação subsequente (PORTUGAL, 2012a) justificou que o Governo procedesse a uma revisão da legislação anterior “com vista a dotar o ordenamento jurídico português de normas que garantam e promovam o reforço progressivo da autonomia e a maior flexibilização organizacional e pedagógica das escolas, condições essenciais para a melhoria do sistema público de educação” (Preâmbulo). Foi afirmado nesse mesmo decreto de que, para isso, contribuiria “a reestruturação da rede escolar, a consolidação e alargamento da rede de escolas com contratos de autonomia, a hierarquização no exercício de cargos de gestão, a integração dos instrumentos de gestão, a consolidação de uma cultura de avaliação e o reforço da abertura à comunidade" (PORTUGAL, 2012a). Foi também enunciado que o aprofundamento da autonomia das escolas se concretizaria "através da celebração de 
contratos de autonomia entre a respetiva escola, o Ministério da Educação e Ciência e outros parceiros da comunidade, nomeadamente, em domínios como a diferenciação da oferta educativa, a transferência de competências na organização do currículo, a constituição de turmas, a gestão de recursos humanos” (PORTUGAL, 2012a).

Um balanço dos efeitos desta legislação focada na autonomia das escolas mostrou que, em 2007, apenas tinham sido estabelecidos 22 contratos de autonomia. Por outro lado, uma análise desses contratos, mostra que eles se confinavam à oferta de um conjunto de atividades apresentadas para justificar o corpo docente a elas afeto. Mais recentemente, em 2018, das 811 unidades orgânicas de educação (agrupamentos de escolas e escolas não agrupadas), 212 são subscritoras de contratos de autonomia. Essa autonomia é relativa aos seguintes domínios: organização e gestão da escola; sucesso escolar dos alunos; combate ao abandono escolar; formação integral dos alunos; integração social e comunitária; cuidados de apoio e guarda; formação vocacional e profissional; desenvolvimento dos talentos, empreendedorismo e abertura à investigação, inovação e excelência (PORTUGAL, 2012b). Em síntese, esta autonomia foca, essencialmente, aspetos relacionados com o currículo escolar.

Como se depreende, e tem sido justificado, a opção de descentralização das decisões curriculares tem na sua base o reconhecimento de que o currículo prescrito a nível nacional, correspondente à tradição centralista do sistema educativo português, não é capaz de responder positivamente às especificidades dos alunos que passaram a estar presentes nos diversos contextos escolares, pelo que passou a ser dada às escolas a possibilidade de conceberem projetos educativos e curriculares que os tivessem em consideração. A regulação desse efeito, e como já atrás foi afirmado, passou a ser feita por processos de avaliação, quer das aprendizagens, quer das escolas.

Recorde-se também, e na linha do que caracterizámos do movimento GERM, estas diretivas políticas, progressivamente, foram sendo influenciadas por avaliações internacionais produtoras de recomendações ou de divulgação de resultados que as foram justificando. São disso exemplo os resultados do PISA, que legitimaram políticas de reforço do ensino-aprendizagem da Matemática e da Língua Portuguesa e as avaliações da OCDE que justificaram, na avaliação externa das escolas, que a atenção fosse concentrada nos resultados académicos dos alunos.

Apesar destas orientações em linha com políticas de accountability (AFONSO, 2009; LIMA, 2010), e que revelam o efeito contaminante do movimento do GERM infecioso, no final dos anos 1990, na transição de séculos, e depois de um movimento que envolveu as escolas num amplo debate sobre a organização e os processos de desenvolvimento dos currículos escolares, designado por “Reflexão participada sobre os currículos”, houve uma medida política que reconheceu as escolas como locais de decisão e os professores como agentes dessas decisões curriculares (LEITE; FERNANDES, 2010; BOLÍVAR, 2012). Definiu essa medida política a possibilidade de "cada escola organizar e gerir, autonomamente, o processo de ensino/aprendizagem, tomando como referência os saberes e as competências nucleares a desenvolver pelos alunos no final de cada ciclo e no final da escolaridade básica, adequando-o às necessidades diferenciadas de cada contexto escolar e 
podendo contemplar a introdução no currículo de componentes locais e regionais” (PORTUGAL, 1999).

A autonomia curricular que se seguiu visou sobretudo o estabelecimento de novos modos de trabalho pedagógico dos professores, novas relações do conhecimento escolar com os conhecimentos do quotidiano e com as experiências culturais dos alunos, isto é, neste aspeto, pareceu constituir uma dinâmica de oposição ao "GERM infecioso". Foi proposto que as escolas e os professores, em função do currículo prescrito a nível nacional, concebessem um projeto curricular de escola ou de agrupamento de escolas que tivesse em consideração quer as especificidades regionais e locais, quer os recursos existentes. Esta exigência nem sempre foi fácil de concretizar, já que implicava alterar culturas de escola e culturas profissionais dos professores, assim como rotinas instituídas, facto que criou dificuldades várias à concretização de um trabalho de equipa capaz de romper com o individualismo docente e com a lógica da centralização e uniformização curricular que imperava no sistema educativo português. Apesar disso, quando as escolas e os professores estavam a iniciar uma nova cultura profissional e institucional em linha com o exercício do poder de agência (PRIESTLEY, 2011; PRIESTLEY; BIESTA; ROBINSON, 2013, 2015), uma alteração do Governo fez regressar ao Ministério da Educação uma orientação centralista fortemente enraizada em políticas tecnicistas e elitistas, contexto que favoreceu a emergência de um discurso marcado por lógicas meritocráticas que justificam que apenas alguns acedam ao sucesso e à excelência.

Num movimento oscilatório, em 2015, com uma nova mudança política do Governo em Portugal, começou a viver-se o regresso a políticas que privilegiam uma educação democrática fundada em princípios de equidade e de uma justiça curricular, promotora da justiça social (SANTOMÉ, 2013; SAMPAIO; LEITE, 2016, 2018). A sua materialização ganhou maior expressão em 2017/2018 com o "Projeto de Autonomia e Flexibilidade Curricular" (PAFC), concretizado formalmente no Despacho no 5908/2017 (PORTUGAL, 2017a). Baseado no pressuposto de que promover sucesso escolar significa promover melhores aprendizagens para todos, o PAFC propôs: passar-se da transmissão e acumulação enciclopedista de conteúdos para um registo caracterizado pela aquisição de competências que permitam ao aluno gerir a complexidade do conhecimento que um mundo em transformação acelerada nos traz.

Nesse sentido o PAFC prevê a possibilidade de as escolas organizarem as atividades letivas de um modo diferente, com novos modelos de organização pedagógica que potenciem e promovam o sucesso educativo. Como é enunciado no referido despacho, as escolas passaram a ter a possibilidade de:

- fundir parcialmente algumas disciplinas ou mesmo criar disciplinas novas (respeitando as matrizes curriculares de base);

- organizar semestralmente as disciplinas;

- criar domínios de autonomia curricular (DAC) que possibilitam dedicar tempo letivo a projetos de natureza interdisciplinar;

- integrar nas matrizes curriculares a disciplina de Cidadania e Desenvolvimento. 
Para a concretização desta política, é conferida às escolas poderem gerir autonomamente até $25 \%$ do currículo. Nas suas intenções, a flexibilidade curricular é justificada para permitir ancorar as aprendizagens dos alunos em práticas pedagógicas que as tornem significativas, e de que são exemplo o trabalho interdisciplinar, o trabalho em projetos e o trabalho de grupo. A par deste projeto, e que o limitam e regulam, foram produzidos novos documentos de referência que as escolas e os professores têm de seguir, entre os quais:

- documentos de orientação curricular (por disciplina e por ano) que focam os conteúdos a lecionar - designados por Aprendizagens Essenciais (PORTUGAL, 2018a);

- o Perfil dos Alunos à Saída da Escolaridade Obrigatória (PORTUGAL, 2017b), que constitui um documento orientador de referência para todo o sistema educativo, e define 10 áreas de competências que se relacionam com as aprendizagens essenciais de cada disciplina ou área curricular.

Face a este cenário complexo, coloca-se a questão: como usam as escolas os professores o seu poder de agência (PRIESTLEY, 2011; PRIESTLEY; BIESTA; ROBINSON, 2013, 2015)? Como tem sido reconhecido, um processo como este não pode ser levado a cabo com êxito sem a participação ativa e o empenho dos professores, e sem lhes serem dadas condições para o exercício de um trabalho colaborativo (LEITE; PINTO, 2016) que favoreça a existência de "novas” estratégias.

Depois de uma fase piloto que envolveu 226 unidades orgânicas, os princípios do PAFC foram generalizados a todas as escolas através do Decreto-Lei $n^{0}$ 55/2018 de 6 de julho (PORTUGAL, 2018b), que estabelece o currículo dos ensinos básico e secundário e de avaliação das aprendizagens.

Em síntese, como revelam as medidas políticas aqui sumariamente descritas, Portugal não fugiu à regra em matéria de "ensaio político" sobre atribuição de maior autonomia às escolas e poder de decisão curricular aos professores. De um modo geral, os primeiros passos são dados em regime de voluntariado que, depois são ampliados a todas as escolas, com carácter obrigatório, e a quem é pedida a prestação de contas através de processos de avaliação. Neste procedimento, correm as escolas e os professores o risco de lhes serem atribuídas responsabilidades e exigidos resultados sem que lhes tenham sido dadas condições para a sua concretização. São estes aspetos que estiveram em foco no estudo empírico que a seguir se apresenta

\section{Procedimentos metodológicos}

O estudo, de natureza qualitativa (AMADO, 2014), visa, como se referiu, identificar e analisar potencialidades e limites da implementação, em 2017/2018, da medida política da autonomia e flexibilidade curricular se constituir uma contracultura ao "GERM infecioso" (SAHLBERG, 2011, 2016). Os dados foram obtidos através da análise de relatórios do 
Projeto de Autonomia e Flexibilidade Curricular (PAFC) elaborados por agrupamentos de escolas que aderiram ao projeto no ano de 2017/2018 (fase piloto da medida política). De um total de 43 agrupamentos da região norte de Portugal, foram analisados 21 relatórios (21R). Os relatórios foram consultados nas plataformas digitais dos respetivos agrupamentos, por estas plataformas serem consideradas um meio credível de divulgação do trabalho das escolas e, concretamente, dos resultados da implementação desta medida curricular. Essas plataformas digitais foram consultadas no período de março a junho de 2019.

A análise de conteúdo (BARDIN, 2008) desses relatórios foi estruturada em duas dimensões e categorias de análise, que a tabela 1 sistematiza.

Tabela 1 - Dimensões e categorias de análise

\begin{tabular}{|c|c|c|}
\hline Designação do documento & Dimensão de análise & Categorias \\
\hline \multirow{7}{*}{$\begin{array}{c}\text { Relatórios de } \\
\text { monitorização/avaliação. }\end{array}$} & \multirow{3}{*}{$\begin{array}{c}\text { Potencialidades do } \\
\text { PAFC }\end{array}$} & $\begin{array}{l}\text { Promoção das aprendizagens dos } \\
\text { alunos }\end{array}$ \\
\hline & & $\begin{array}{l}\text { Desenvolvimento } \\
\text { Curricular }\end{array}$ \\
\hline & & Trabalho docente \\
\hline & \multirow{4}{*}{ Limites do PAFC } & Trabalho docente \\
\hline & & $\begin{array}{l}\text { Práticas de avaliação de } \\
\text { aprendizagem }\end{array}$ \\
\hline & & $\begin{array}{l}\text { Entreposto cultural: escola e } \\
\text { comunidade }\end{array}$ \\
\hline & & Monitorização do PAFC \\
\hline
\end{tabular}

Fonte: Elaboração dos Autores, 2019

No acesso à informação e na sua análise, foram tidos em consideração aspetos éticos de modo a não identificar os agrupamentos, garantindo-lhes o anonimato. Por isso, para cada categoria, os dados são referenciados por relação com o número de relatórios em que esse aspeto é focado. Por exemplo, aspetos relacionados com a categoria "Práticas da avaliação da aprendizagem” são referenciados em 21 relatórios - (21R), isto é, em todos os relatórios analisados.

\section{Apresentação e análise de dados}

Neste ponto, apresentam-se e discutem-se os dados provenientes da análise de conteúdo dos relatórios de avaliação do PAFC realizados por agrupamentos de escolas no final do primeiro ano da sua implementação (2017/2018). Focalizando a atenção nos aspetos enunciados como potencialidades, a "promoção das aprendizagens” é referenciada em todos os relatórios (21R), como um efeito muito positivo decorrente da inovação curricular implementada nos agrupamentos de escolas. Os documentos analisados indicam que as escolas consideram que o PAFC potencia a "flexibilidade e a autonomia na gestão do currículo" (21R), possibilitando, assim, uma “formação de caráter integral e 
multidimensional” (17R) e a realização de "aprendizagens mais significativas para todos os alunos” (14R). O “trabalho de projeto” é referenciado em todos os relatórios analisados (21R) como metodologia principal dos “processos de ensino-aprendizagem”, sustentada em “ações colaborativas entre alunos e professores”.

No que respeita ao desenvolvimento curricular, a análise realizada permitiu identificar um conjunto de aspetos considerados potencialidades desta medida política e de que são exemplo:

- Apropriação “contextualizada do currículo” e redefinição de "ações que se adequam ao contexto"; (19R)

- Integração de "novas metodologias", diferenciando a "organização de tempos e espaços curriculares”; (16R)

- Integração e “articulação disciplinar” e das “metodologias de trabalho projeto”; (21R)

- Promoção da concretização de “interdisciplinaridade-multidisciplinaridade como uma das estratégias” para a gestão e desenvolvimento do currículo; (9R)

- “Diversificação de metodologias de ensino”. (11R)

Estes aspetos enunciados nos relatórios deixam transparecer que o PAFC parece estar a trazer para as escolas, e para os seus agentes, possibilidades concretas de novas formas de reorganização pedagógica e curricular, assim como a promoção de metodologias de trabalho e de ensino diferenciadas e contextualizadas às situações reais vivenciadas em cada contexto escolar. Dessa forma, ao mesmo tempo que o PAFC parece fortalecer o poder de "agência" (PRIESTLEY, 2011; PRIESTLEY; BIESTA; ROBINSON, 2013, 2015) dos professores, transformando-os em autores curriculares, parece, igualmente, estar a contribuir para processos educativos pautados por mais equidade e justiça curricular (SANTOMÉ, 2013; SAMPAIO; LEITE, 2016, 2018) e que possam contribuir para a melhoria das aprendizagens dos alunos. Neste sentido, poder-se-á inferir que o PAFC parece estar a constituir-se num facilitador de ações organizacionais, pedagógicas e curriculares contextualizadas que se contrapõem a uma ordem curricular global estandardizada, e que tem privilegiado a performatividade (Ball, 2003).

Relativamente à categoria trabalho docente, todos os relatórios apontam que o PAFC potenciou a "reflexão sobre processos de diferenciação pedagógica” (21R) e sobre as práticas de “avaliação das/para as aprendizagens” (21R) vivenciados na cultura escolar, fazendo sentir necessidades de mudança. Esta possibilidade de reflexão dos professores é também destacada por Cosme (2018), no relatório de avaliação do PAFC, quando afirma que o projeto permitiu o "desenvolvimento profissional dos professores através da reflexão dos modelos pedagógicos, incentivando-se o reforço da intencionalidade pedagógica e alterando uma visão rígida acerca do currículo e das práticas pedagógicas” (COSME, 2018, p. 23). Nessa perspetiva, é reconhecido que os professores, por meio das experiências vividas na concretização desta medida política, tiveram a oportunidade de fortalecer diálogos com as suas práticas e, nesse sentido, refletir sobre as problemáticas que lhe estão subjacentes. Esta situação, como sustentam Axer, Frangella e Rosário (2017) pode potenciar a ressignificação 
das conceções e perspetivas de conhecimento que constituem as matrizes dos professores, assim como os sentidos que atribuem ao currículo e à docência contribuindo, desse modo, para potencializar a reconstrução e o desenvolvimento do currículo e das ações pedagógicas.

Ainda que os documentos analisados apontem para potencialidades de reflexão dos professores sobre as suas práticas, a análise permitiu também sinalizar constrangimentos relacionados, nomeadamente, com a insegurança causada pela exigência de "abandono de rotinas" (7R), com o imperativo de "trabalho colaborativo entre docentes" (14R) de diferentes “áreas disciplinares e da interdisciplinaridade na realização de projetos” (9R) centrados nos alunos, assim como com a falta de "tempo para a preparação e reflexão de estratégias” (R18) a utilizar.

Destacam-se neste domínio aspetos relacionados com as práticas de avaliação da aprendizagem desenvolvidas em conciliação com a filosofia curricular de base do PAFC, apontados como principais limites ao trabalho das escolas e dos professores (COSME, 2018). Com efeito, uma das limitações identificada em todos os relatórios tem a ver com a dificuldade de escolas e professores desconstruírem “conceções e práticas de avaliação” que possam potenciar processos de "qualidade e exigência” (21R) adequados ao PAFC. Relacionados com esta limitação são identificados outros aspetos que dão conta de sentimentos de “desconfiança dos professores, alunos e famílias” relativamente à proposta curricular, nomeadamente ao nível “das lógicas de avaliação em curso” concretizadas por “exames nacionais” e cujas classificações “condicionam o acesso ao ensino superior” (17R).

Parece poder depreender-se que, pese embora o caráter inovador que subjaz ao PAFC, e as possibilidades que parece ter introduzido de maior reflexão dos professores sobre o seu trabalho, não permitiu ainda desinstalar a cultura do GERM enraizada nas escolas. Esta matriz cultural e cristalizada na cultura escolar tem vindo a fortificar-se através de um "entreposto cultural" (TORRES, 2008) que tem trespassado a escola e a comunidade, e que assenta em referenciais culturais de uma "cultura de testagem" (BROADFOOT; BLACK, 2004; STOBART, 2008; MARINHO; LEITE; FERNANDES, 2013), em que as exigências das famílias se aportam a sentidos de sucesso impostos por políticas de uma agenda global que orienta a educação.

Como tem sido sustentado, essa agenda global tem remetido para lógicas educacionais com acentuação nos valores quantitativos obtidos pelos alunos em exames nacionais e testes internos - “cultura global do número” (MARINHO, 2014). É esta cultura que tem apoiado a opção por práticas curriculares assentes na padronização e no treino dos conteúdos a serem testados, quer nas avaliações de aprendizagem internas, isto é, nas que são realizadas pelas escolas, quer nas externas, as que se referem a exames nacionais e a testes internacionais (PACHECO, 2019; MARINHO, LEITE; FERNANDES, 2017). Estas avaliações, assentes em rankings nacionais e internacionais, expõem as escolas e os professores que não ocupam os primeiros lugares das tabelas a imagens depreciativas, sendo tomadas como verdades por uma sociedade com valores de essência em um capital desumano (SALTMAN, 2009). É nesse sentido que tem vindo a reconhecer-se que a pressão da avaliação externa das aprendizagens dos alunos e das escolas tem contribuído, ao longo dos tempos, para 
conceções, crenças e práticas de avaliação do desempenho dos estudantes pouco formativas (LEITE; FERNANDES, 2014; COSME, 2018).

A análise realizada no estudo que neste artigo está a ser apresentado situa-se em linha com este posicionamento ao constatar-se, entre outros aspetos já referidos, um conjunto de constrangimentos relacionados com a dificuldade de "avaliar efeitos" ao nível das "competências transversais e da cidadania” (16R), que colocam limites às possibilidades desta medida política atuar como contracultura do "GERM infecioso". Por contraponto a esses limites, foram identificados aspetos que parecem configurar recomendações para o poder político quanto às regras de avaliação em curso, e de que são exemplo:

- Aprofundar um "sistema de avaliação dos impactos" gerados no desenvolvimento e mobilização das "competências transversais durante e após o percurso de aprendizagem" dos alunos, tendo em conta os exames; (7R)

- "Elaborar instrumentos para a entrada do ensino secundário", que permitam "posicionar os alunos ao nível das competências transversais"; (9R)

- Encontrar formas de "avaliar a disciplina de Cidadania e Desenvolvimento", face à dificuldade em "atribuir uma classificação de 0 a 20" que é "contabilizada para a média do ensino secundário”. (12R)

Dos registos analisados parece, pois, depreender-se que existe uma tensão entre as práticas de avaliação externa e a interna e os princípios curriculares e pedagógicos do PAFC. Sendo esta medida política justificada na intenção de proporcionar o desenvolvimento nos alunos de competências transversais e de aprendizagens para o exercício de uma cidadania ativa, a sua concretização mostra estar a colocar dificuldades, entre outras, ao nível de instrumentos e de procedimentos de avaliação das competências transversais e de concretização de formação no âmbito da cidadania e desenvolvimento, que pretende ser transversal a várias disciplinas. É nesse sentido que 12 relatórios destacam a dificuldade em conciliar estas dimensões de formação com o currículo do $10 .^{\circ}$ ano de escolaridade e onde é muito sentida a pressão das provas de avaliação dos exames nacionais que interferem no acesso ao ensino superior.

Ainda a propósito da avaliação da aprendizagem, é assinalada, pelas escolas, a dificuldade em "definir descritores que posicionem os alunos segundo níveis de desempenho", em cada "nível de ensino", tendo em conta as "aprendizagens essenciais" (17R) e o que a legislação portuguesa define para o perfil do aluno à saída da escolaridade obrigatória (SOUSA-PEREIRA; LEITE, 2019). Esta situação justifica que Cosme (2018), no relatório elaborado sobre esta medida política, sustente que os desafios relativos à avaliação da aprendizagem remetem para "problemas concetuais e praxeológicos que devem merecer uma atenção particular, no âmbito dos processos de monitorização dos projetos PAFC" (COSME, 2018, p. 42). A par desta recomendação, esta académica reforça também que estamos perante uma "problemática complexa, marcada por tensões diversas, e eventualmente alguns equívocos, que merece ser encarada como um processo de formação a viver coletivamente, no âmbito do desenvolvimento do PAFC” (COSME, 2018, p. 55). 
É também dentro deste quadro de complexidades e de entreposto cultural (TORRES, 2008) que se compreendem os limites resultantes dos constrangimentos apontados pelas escolas, no que se refere ao trabalho a desenvolver com os pais quanto ao "reconhecimento da mais-valia dos Domínios de Autonomia Curricular (DAC)" (8R), no "desenvolvimento de competências múltiplas dos alunos” (4R), no âmbito do PAFC e, concomitantemente, no apoio na "apropriação do projeto por toda a comunidade educativa" (15R).

Em nossa opinião, e corroborando Cosme (2018), os constrangimentos vivenciados pelas escolas poderão ser minimizados através de uma monitorização e apoio regular e efetivo por parte da administração central e pelos vários órgãos de gestão escolar (direção, departamentos curriculares, grupos disciplinares e conselhos de turma) nas várias dimensões de desenvolvimento do PAFC. A este nível, os relatórios das escolas apontam também constrangimentos associados à monitorização do PAFC, referindo, entre outros aspetos, a necessidade de "desenvolver formação contínua" concreta e "válida nos contextos de ação" (16R), a existência de um "acompanhamento sistemático das equipas docentes" (18R), que as "capacitem e apoiem a construção de lideranças" (8R) substanciais.

Em síntese, a análise realizada permitiu identificar potencialidades e constrangimentos, decorrentes da implementação PAFC, que se configuram em possibilidades e limites desta política curricular. As possibilidades situam-se ao nível da autonomia que é conferida às escolas e aos professores para, usando o poder de agência nas decisões curriculares (RIESTLEY, 2011; PRIESTLEY, BIESTA; ROBINSON, 2013, 2015), contribuírem para uma justiça curricular e social (SANTOMÉ, 2013; SAMPAIO; LEITE, 2016, 2018) e geradora de melhores aprendizagens dos alunos. Quanto aos limites é destacar o sentimento de desconfiança de professores, alunos e famílias face à "bondade" da medida política.

\section{Considerações finais}

Tendo o estudo como objetivo identificar potencialidades e limites da política de autonomia e flexibilidade curricular - em curso em Portugal desde 2017/2018 - constituir uma medida contra hegemónica ao GERM e a culturas escolares da tradição deste país, os dados recolhidos e interpretados mostraram a existência de possibilidades, mas também de limites. Trata-se de uma política que, se por um lado, abre possibilidades às escolas e aos professores se assumirem como agentes de decisões que contemplem as situações reais com que convivem, por outro, na sua concretização, há um conjunto de constrangimentos provenientes, quer de culturas organizacionais e modos de trabalho docente ainda assentes em lógicas tradicionais, quer da existência de outras medidas políticas orientadas para avaliações externas e metas não conciliáveis com a filosofia curricular de base do PAFC.

Clarificando esta tensão, e como se tornou evidente na análise dos dados recolhidos e que expressam as opiniões de agrupamentos de escolas envolvidos neste projeto curricular, o PAFC trouxe possibilidades às escolas e aos professores para uma contextualização do currículo prescrito a nível nacional (FERNANDES et al., 2013) e para a diversificação de 
metodologias de ensino e a realização de práticas interdisciplinares, que procuram a melhoria das aprendizagens dos alunos. No entanto, e como também ficou claro, a par destes aspetos positivos, foram igualmente identificados constrangimentos que se prendem, quer com a dificuldade de alteração de práticas curriculares e de ser instituído o trabalho colaborativo entre professores, quer com a existência de condições que as favoreçam na concretização.

Os dados mostram ainda, e como tensão mais forte, os constrangimentos que decorrem das avaliações externas a que são sujeitos os alunos e as escolas. A pressão exercida pelos resultados académicos obtidos nos exames nacionais e nos testes internacionais mostra quão forte e difícil é romper com este "GERM infecioso" (SAHLBERG, 2011) que aprisiona as escolas e os seus agentes em conceções e práticas curriculares padronizadas. É esta aculturação que tem remetido as escolas e os professores para processos de (re)produção de currículos e avaliações que emanam de organizações transacionais e que impõem outputs assentes em ordens e lógicas hegemónicas globais que ignoram as especificidades locais.

Ultrapassar esta situação reclamará um envolvimento efetivo de todos na desconstrução de referenciais culturais, organizacionais e profissionais cristalizados e na procura de novas formas de trabalho que potenciem práticas curriculares fundadas no exercício da autonomia das escolas e dos professores e nas condições para a concretizarem numa relação direta com as situações relativas a cada contexto escolar e social.

Como Cosme (2018), sustentamos que no terreno deverá ser assumido um forte compromisso, tanto pelo Ministério da Educação, como pelas escolas e seus agentes, num acompanhamento efetivo em que os constrangimentos identificados sejam transformados em investimentos na produção de meios, estratégias e dispositivos potenciadores da sua transformação. Nesta perspetiva, consideramos que o PAFC poderá constituir-se em um potencial antídoto neutralizador de efeitos que o "GERM infecioso" tem provocado nas culturas escolares e, concomitantemente, nas famílias e comunidades educativas em geral, e que têm (re)alimentado princípios de uma sociedade homogénea e homogeneizadora.

Nesse âmbito, o estudo leva-nos a sustentar que o caminho que se poderá construir a partir da medida política de Autonomia e Flexibilidade Curricular, que em 2018/2019 foi alargado a todas as escolas portuguesas, justifica estudos de investigação-ação a realizar pelos próprios agentes em contextos de ação, no sentido de paulatinamente (re)descobrirem e (re)construirem mecanismos e estratégias que possam neutralizar e reverter os efeitos dos constrangimentos vividos e, em simultâneo, consolidarem as potencialidades do PAFC já identificadas. Destaca-se ainda a importância dos relatórios realizados pelos agrupamentos de escolas no final do primeiro ano de implementação desta medida curricular, reconhecendo que as informações neles contidas sejam tidas em atenção pela Tutela. Neste desejo, esperamos que o estudo a que se reporta este artigo contribua também para esse fim.

\section{Nota}

1. O PISA (Programme for International Student Assessment), o TIMSS (Trends in International Mathematics and Science Study e o PIRLS (Progress in International Reading Literacy Study) são exemplos de testes padronizados que têm influenciado políticas de uma educação global. 


\section{Referências}

AMADO, João. Manual de investigação qualitativa em educação. Coimbra: Imprensa da Universidade de Coimbra, 2014.

AFONSO, Almerindo J. Para uma concetualização alternativa de accountability em educação. Educ. Soc., v. 33, n. 119, p. 471-484, 2012.

AFONSO, Almerindo J. Nem tudo o que conta em educação é mensurável ou comparável: crítica à accountability baseada em testes estandardizados e rankings escolares. Revista Lusófona de Educação, n. 13, p. 13-29, 2009.

AXER, Bonnie; FRANGELLA, Rita de Cássia Prazeres; ROSÁRIO, Roberta Sales Lacê. Políticas curriculares em uma lógica centralizadora e escapes possíveis: tecendo outras redes políticas. Revista e-Curriculum, v. 15, n. 4, p. 1176-1207, 2017. DOI http://dx.doi.org/10.23925/1809-3876.2017v15i4p1176-1207.

BALL, Stephen J. Educação Global S. A.: novas redes de políticas e o imaginário neoliberal. Tradução de Janete Bridon. Ponta Grossa: UEPG, 2014.

BALL, Stephen J. The Teacher's soul and the terrors of performativity. Journal of Education Policy, v. 18, n.2, p. 215-228, 2003.

BALL, Stephen. Diretrizes e políticas globais e relações políticas locais em educação. Currículo sem Fronteiras, v. 1, n. 2, p. 99-116, 2001.

BARDIN, Laurence. Análise de conteúdo. Lisboa: Edições 70 Lda., 2008.

BARREIRA, Carlos; PINTO, Jorge. A Investigação em Portugal sobre a avaliação das aprendizagens dos alunos (1990-2005). Investigar em Educação - Revista da Sociedade Portuguesa de Ciências da Educação, nº4, p. 21-105, 2005.

BARROSO, João. O estudo da autonomia da escola: da autonomia decretada à autonomia construída. In: João Barroso (org.). O Estudo da Escola. Porto: Porto Editora, p. 167-189, 1996.

BOLÍVAR, Antonio. Melhorar os processos e os resultados educativos. O que nos ensina a investigação. Porto: Fundação Manuel Leão, 2012.

BROADFOOT, P.; BLACK, P. Redefining assessment? The first ten years of assessment in education. Assessment in Education, v. 11, n. ${ }^{\circ}$ 1, p. 7-27, 2004.

COSME, Ariana. Projeto de Autonomia e Flexibilidade Curricular (PAFC): estudo avaliativo da experiência pedagógica desenvolvida em 2017/2018 ao abrigo do despacho No 5908 / 2017. Porto: Faculdade de Psicologia e Ciências da Educação da Universidade do Porto, 2018.

DALE, Roger. A globalização e o desenho do terreno curricular. Revista Espaço do Currículo, v. 1, n.1, p. 12-33, 2008.

FERNANDES, Preciosa; LEITE, Carlinda; MOURAZ, Ana; FIGUEIREDO, Carla. Curricular contextualization: Tracking the meanings of a concept. The Asia-Pacific Education Researcher, v. 22, n. 4, p. 417-425, 2013. doi:10.1007/s40299-012-0041-1 
FIGUEIREDO, Carla; LEITE, Carlinda; FERNANDES, Preciosa. Entre os enunciados políticos e os corredores de liberdade nas práticas curriculares dos professores. Educ. Pesqui., v. 45, e189917, 2019. Doi 10.1590/S1678-4634201945189917

FRANGELLA, Rita de C. P.; DIAS, Rosanne E. Os sentidos de docência na BNCC: efeitos para o currículo da educação básica e da formação/atuação de professores, Educação Unisinos, v. 22, n.1, p. 7-15, 2018. Doi: 10.4013/edu.2018.221.01

FULLER, Kay; STEVENSON, Howard. Global education reform: understanding the movement. Educational Review, v. 71, n. 1, p. 1-4, 2019. DOI: 10.1080/00131911.2019.1532718

FULLER, Kay. That would be my red line”: an analysis of headteachers' resistance of neoliberal education reforms. Educational Review, v. 71, n.1, p. 31-50, 2018.

KAMENS, David H.; MCNNELY, Connie L. Globalization and the Growth of International Educational Testing and National Assessment. Comparative Education Review, v. 54, n.1, p. 5-25, 2010.

KLEIN, Naomi. The Shock Doctrine: The Rise of Disaster Capitalism. New York: Henry Holt and Company, Inc., 2008.

KUEHN, Larry. GERM infects education globally. 2014. Acesso a 5 de agosto de 2019 em https:/bctf.ca/uploadedFiles/Public/SocialJustice/Programs/ISP/Globalization/GERM_infects_education_ globally.pdf

LEITE, Carlinda; PINTO, Carmem. O trabalho colaborativo entre os professores no quotidiano escolar. Educação, Sociedade \& Culturas, n.48, p. 69-91, 2016.

LEITE, Carlinda; FERNANDES, Preciosa. Avaliação, qualidade e equidade. Avaliação: Revista da Avaliação da Educação Superior, v. 19, n. 2, p. 421-438, 2014.

LEITE, Carlinda; FERNANDES, Preciosa. Curricular studies and their relation with the political agenda for education. Transnational Curriculum Inquiry, v. 9, n.2, p. 35-49, 2012.

LEITE, Carlinda; FERNANDES, Preciosa. Desafios aos professores na construção de mudanças educacionais e curriculares: Que possibilidades e que constrangimentos. Educação - PUCRS, v. 33, n. 3, p. 198-204, 2010.

LEITE, Carlinda; FERNANDES, Preciosa. Desafios para um currículo escolar comprometido com a inclusão. Educação: Temas e Problemas, n.3, p. 203-215, 2007.

LIMA, Licínio. Gestão, autonomia e accountability na escola pública portuguesa: breve diacronia. RBPAE v. 26, n.1, p. 13-30, 2010.

LOPES, Alice C. (2019). Articulações de demandas educativas (im)possibilitadas pelo antagonismo ao “marxismo cultural”. Arquivos Analíticos de Políticas Educativas, v. 27, n.109, p.1-21, 2019. https://doi.org/10.14507/epaa.27.4881

MACEDO, Elizabeth. Fazendo a Base virar realidade: competências e o germe da comparação. Retratos da Escola, v. 13, n. 25, p. 39-58, 2019. DOI: 10.22420/rde.v13i25.967

MARINHO, Paulo; LEITE, Carlinda; FERNANDES, Preciosa. Mathematics summative assessment practices in schools at opposite ends of performance rankings in Portugal, Research in Mathematics Education, v. 19, n. 2, 184-198, 2017. https://doi.org/10.1080/14794802.2017.1318085 
MARINHO, Paulo. A avaliação da aprendizagem no ensino básico: contributos para a compreensão da sua relação com o sucesso escolar. Tese de Doutoramento. Faculdade de Psicologia e de ciências de Educação da Universidade do Porto, 2014.

MARINHO, Paulo; LEITE, Carlinda; FERNANDES, Preciosa (2013). A avaliação da aprendizagem: um ciclo vicioso de Testinite. Est. Aval. Educ., v. 24, n. 55, p. 304-334, 2013.

PACHECO, José Augusto; MAIA, Ilda, B. (2019). Avaliação das aprendizagens no contexto de políticas curriculares de accountability. Linhas Críticas, v. 25, p. 133-152, 2019. https://doi.org/10.26512/lc.v25i0.23778

PORTUGAL. Despacho no 6944-A/2018 de 19 de julho de 2018. Homologa as Aprendizagens Essenciais do ensino básico. Educação - Gabinete do Secretário de Estado da Educação Diário da República n. ํ 138/2018, $1^{\mathrm{o}}$ Suplemento, Série II de 19 de julho de 2018a.

PORTUGAL. Decreto-Lei no 55/2018 de 6 de julho de 2018. Estabelece o currículo dos ensinos básico e secundário e os princípios orientadores da avaliação das aprendizagens. Presidência do Conselho de Ministro. Diário da República n. ${ }^{\circ}$ 129/2018, Série I de 6 de julho de 2018b.

PORTUGAL. Despacho n 5908/2017 de 5 de julho de 2017. Autoriza, em regime de experiência pedagógica, a implementação do projeto de autonomia e flexibilidade curricular dos ensinos básico e secundário, no ano escolar de 2017-2018. Gabinete do Secretário de Estado da Educação. Diário da República n. . 128/2017, Série II de 5 de julho de 2017a.

PORTUGAL. Despacho no 6478/2017 de 26 de julho de 2017. Homologa o Perfil dos Alunos à Saída da Escolaridade Obrigatória. Educação - Gabinete do Secretário de Estado da Educação. Diário da República n. ${ }^{\circ}$ 143/2017, Série II de 26 de julho de 2017b.

PORTUGAL. Decreto-Lei $n^{\circ}$ 137/2012 de 2 de julho de 2012. Altera (segunda alteração) o Decreto-Lei 75/2008, de 22 de abril, que aprova o regime jurídico de autonomia, administração e gestão dos estabelecimentos públicos da educação pré-escolar e dos ensinos básico e secundário, e procede à sua republicação. Ministério da Educação e Ciência. Diário da República n. ${ }^{\circ}$ 126/2012, Série I de 2 de julho de 2012a.

PORTUGAL. Portaria n. ${ }^{0}$ 265/2012, de 30 de agosto. Define as regras e procedimentos a observar quanto à celebração, acompanhamento e avaliação dos contratos de autonomia a celebrar entre os agrupamentos de escolas ou escolas não agrupadas e o Ministério da Educação e Ciência. Ministério da Educação e Ciência. Diário da República n. ${ }^{\circ}$ 168/2012, Série I de 30 de agosto de 2012b.

PORTUGAL, Decreto-Lei no 75/2008 de 22 de abril de 2008. Aprova o regime de autonomia, administração e gestão dos estabelecimentos públicos da educação pré-escolar e dos ensinos básico e secundário. Ministério da Educação. Diário da República n. ${ }^{0}$ 79/2008, Série I de 22 de abril de 2008.

PORTUGAL, Despacho no 9590/99 de 14 de maio de 1999. Actualiza os princípios reguladores e orientadores (publicados em anexo) dos projectos de gestão flexível dos currículos dos estabelecimentos do ensino básico. Ministério da Educação. Diário da República - 2. ${ }^{a}$ Série, Nº 112, de 14.05.1999, p. 7217, de 14 de maio de 1999.

PORTUGAL. Decreto-Lei $n^{0}$ 172/91, de 10 de Maio de 1991. Aprova o regime jurídico de direcção, administração e gestão escolar. Ministério da Educação. Diário da República n. ${ }^{\circ}$ 107/1991, Série I-A de 10 de maio de 1991.

PORTUGAL, Decreto-Lei no 43/1989 de 3 de fevereiro de 1989. Estabelece o regime jurídico da autonomia das escolas oficiais dos $2 .^{\circ}$ e $3 .^{\circ}$ ciclos do ensino básico e do ensino secundário. Ministério da Educação. Diário da República n. ${ }^{\circ}$ 29/1989, Série I de 3 de fevereiro de 1989. 
PORTUGAL. Lei no 46/86 de 14 de outubro de 1986. A Assembleia da República decreta, nos termos da alínea d) do artigo $164 .^{\circ}$ e da alínea e) do artigo $167 .^{\circ}$ da Constituição a Lei de Bases do sistema Educativo. Diário da República n. ${ }^{\circ}$ 237/1986, Série I de 14 de outubro de 1986.

PRIESTLEY, Mark; BIESTA, Gert; ROBINSON, Susan. Teacher agency: What is it and why does it matter?. In R. Kneyber e J. Evers, Flip the system: Changing education from the bottom up, p. 134-148. London: Routledge, 2015.

PRIESTLEY, Mark; BIESTA, Gert; ROBINSON, Susan. Teachers as agents of charge: Teacher agency and emergigng models of curricum. In M. Priestley, e G. Biesta, Reiventing the curriculum: New trends in curriculim police and practice, p. 187-206. London: Bloomsbury Academic, 2013.

PRIESTLEY Mark. Schools, teachers and curriculum change: a balancing act? Journal of Educational Change, v. 12, n., p. 1-23, 2011.

REIS, G.R.F.S.; CAMPOS, M.S.N.; FLORES, R.L.P. Currículo em tempos de Escola sem Partido: Hegemonia disfarçada de neutralidade. Revista Espaço do Currículo, v. 9, n. 2, p. 200-214, 2016.

ROBERTSON, S. L. What teachers need to know about the global education reform movement. In: LITTLE, G. (Ed.). Global education “reform”. Building resistance and solidarity. Croydon: Manifesto Press, 2015. p. $10-17$.

SAHLBERG, Pasi. The Global Educational Reform Movement and Its Impact on Schooling. In Karen Mundy ; Andy Green: Bob Lingard e Antoni Verger (Eds.). The Handbook of Global Education Policy, p.128144, 2016.

SAHLBERG, Pasi. Finnish lessons: What can the world learn from educational change in Finland? New York, NY: Teachers College Columbia University, 2011.

SAHLBERG, P. Education reform for raising economic competitiveness. Journal of Educational Change, v. 7, n. 4, p. 259-287, 2005.

SALTMAN K.J. Schooling in Disaster Capitalism: How the Political Right Is Using Disaster to Privatize Public Schooling. In: Macrine S.L. (eds) Critical Pedagogy in Uncertain Times. Education, Politics, and Public Life. Palgrave Macmillan, New York, p. 27-54, 2009.

SAMPAIO, Marta; LEITE, Carlinda. Mapping social justice perspectives and their relationship with curricular and schools' evaluation practices: Looking at scientific publications. Education as Change, v. 22, n.1, p. $1-2,2018$.

SAMPAIO, Marta; LEITE, Carlinda. A Avaliação Externa das Escolas e os TEIP na sua relação com a justiça social. Educação, Sociedade \& Culturas, nº 47, p. 115-136, 2016.

SANTOMÉ, Jurjo T. Currículo escolar e justiça social: O cavalo de Troia da educação. Porto Alegre: Penso, 2013.

SELLAR, Sam; LINGARD, Bod. The OEDC and global governance in education. Journal of Education Policy, v. 28, n. 25, p.710-725, 2013. https://doi.org/10.1080/02680939.2013.779791

SCHNEIDER, Marilda Pasqual; NARDI, Elton Luiz (2015). Accountability em educação: mais regulação da qualidade ou apenas um estágio do Estado-avaliador?. ETD - Educação Temática Digital, v. 17, n. 1, p. 58-74, 2015. https://doi.org/10.20396/etd.v17i1.8634818

SOUSA-PEREIRA, Fátima; LEITE, Carlinda (2019). Política do perfil dos alunos à saída da escolaridade obrigatória e desafios para a formação de professores. Revista de Educação, Ciência e Cultura, v. 24, n. 1, 113-122, 2019. http://dx.doi.org/10.18316/recc.v24i1.5603 
STOBART, G. Testing times: the uses and abuses of assessment. Oxon: Routledge, 2008.

THIESEN, Juares da Silva. A gestão do currículo nas malhas das redes políticas em escala transnacional. Revista Teias, v. 17, n. 47, 2016. DOI: 10.12957/teias.2016.25897.

TORRES, Leonor. A escola como entreposto cultural: o cultural e o simbólico no desenvolvimento democrático da escola. Revista Portuguesa de Educação, v. 21, n. 1, p. 59-81, 2008.

VERGER, Antoni; PARCERISA, Luís; FONTDEVILA, Clara. Crescimento e disseminação de avaliações em larga escala e de responsabilizações baseadas em testes: uma sociologia política das reformas educacionais globais. Rev. FAEEBA - Ed. e Contemp., v. 27, n. 53, p. 60-82, 2018.

VERGER, Antoni; PARCERISA, Luís; ZANCAJO, Adrián. The Privatization of Education - A Political economy of Global Education Reform. New York: Teachers College Press, 2016.

\section{Correspondência}

Paulo Marinho: Doutor em Ciências da Educação, Professor Colaborador no Programa de Pós Graduação em Educação na Universidade Federal de Alagoas (UFAL), Brasil e Investigador do Centro de Investigação e Intervenção Educativas (CIIE) da Faculdade de Psicologia e de Ciências da Educação da Universidade do Porto (FPCEUP), Portugal. Membro da Comunidade de Prática de Investigação - Currículo, Avaliação, Formação e Tecnologias Educativas (CAFTe/CIIE/FPCEUP).

E-mail: pmtmarinho@fpce.up.pt

Carlinda Leite: Doutora em Ciências da Educação, Professora Catedrática na Faculdade de Psicologia e de Ciências da Educação da Universidade do Porto (FPCEUP), investigadora sénior do Centro de Investigação e Intervenção Educativas (CIIE) a cuja direção pertence. Coordenadora da Comunidade Prática de Investigação: Currículo, Avaliação, Formação e Tecnologias Educativas (CAFTe). Presidente da Comissão de Ética da FPCEUP e avaliadora da Agência de Avaliação e Acreditação do Ensino Superior (A3ES).

E-mail: carlinda@fpce.up.pt

Preciosa Fernandes: Doutora em Ciências da Educação, professora na FPCEUP e investigadora do Centro de Investigação e Intervenção Educativas (CIIE) - sendo co-coordenadora da Comunidade Prática de Investigação: Currículo, Avaliação, Formação e Tecnologias Educativas (CAFTe) deste centro de investigação.

E-mail: preciosa@fpce.up.pt

Texto publicado em Currículo sem Fronteiras com autorização dos autores 